\title{
PRÉ-TRATAMENTO DE SEMENTES DE Urochloa brizantha COM PACLOBUTRAZOL
}

Diego Peratelli Ederli, Fabiana Lima Abrantes, Rafaela Torquato de Agostini, Edna Antonia Torquato de

Agostini, Ceci Castilho Custódio

Universidade do Oeste Paulista - UNOESTE, Curso de Agronomia, Presidente Prudente, SP. E-mail: ceci@unoeste.br

\section{RESUMO}

O objetivo do trabalho foi verificar o efeito do pré-tratamento de sementes, via pulverização com paclobutrazol, em sementes de Urochloa brizantha cv. Marandú, em duas situações, com e sem deficiência de água, sobre a germinação e desenvolvimento inicial das plântulas. As sementes foram expostas de maneira uniforme a uma pulverização com 0, 21, 42, 84 e $168 \mathrm{mg} \mathrm{L}^{-1}$ de paclobutrazol (PBZ) na proporção de $10 \mathrm{~mL}$ de solução por quilograma de semente. Após o tratamento as sementes foram colocadas para secar à sombra, e em seguida realizada a instalação do teste de germinação. Os resultados indicaram que a germinação máxima foi na dose de $105 \mathrm{mg} \mathrm{L}^{-1}$ de PBZ e que as doses para o teste de tolerância a deficiência de água seriam as de 84 e $168 \mathrm{mg} \mathrm{L}^{-1}$. Com as sementes tratadas e o controle, foi realizado o teste de germinação por plântulas normais (GPN) nos potenciais osmóticos de $0,-0,3,-0,6$ e $-0,9 \mathrm{MPa}$. Na germinação por protrusão de raiz (GPR) e índice de velocidade de germinação (IVG) utilizaram-se $0,-0,3,-$ 0,6 e -1,2 MPa. A restrição hídrica reduz a GPN, GPR e IVG. O pré-tratamento das sementes favorece a GPN e GPR em condição de restrição hídrica, respectivamente, até -0,9 MPa e -0,6 MPa. A semente tratada com PBZ tem potencial para alcançar, em condição de restrição hídrica, a germinação final semelhante à obtida na ausência de restrição hídrica.

Palavras-chave: estresse hídrico; forrageira; germinação; Marandú; pulverização.

\section{PRE-TREATMENT OF Urochloa brizantha SEEDS WITH PACLOBUTRAZOL}

\begin{abstract}
The objective of the work was to verify the pre-treatment, by spraying, with paclobutrazol solutions in seeds of Urochloa brizantha cv. Marandú, in two situations, with and without water deficiency, upon germination and seeding development. Seeds were uniformly exposed to a spray with 0, 21, 42,84 and 168 $\mathrm{mg} \mathrm{L}^{-1}$ of paclobutrazol (PBZ) in the proportion of $10 \mathrm{~mL}$ of solution per kilogram of seed. After the treatment, the seeds were shaded dried and then installed the germination test. The results showed that the maximum germination was in the $105 \mathrm{mg} \mathrm{L}^{-1}$ de PBZ and the doses of 84 e $168 \mathrm{mg} \mathrm{L}^{-1}$ were chosen to the water deficiency test. With treated seeds and control were performed germination test by normal seedlings evaluation (GNS) in the osmotic potentials of $0,-0.3,-0.6$ and $-0.9 \mathrm{MPa}$. For germination by root protrusion evaluation (GRP) and germination speed index (GSI) the potentials were $0,-0.3,-0.6$ and -1.2 $\mathrm{MPa}$. The water restriction decreases the GNS, GRP and GSI. The pre-treatment with PBZ increases GNS e GRP in water restriction conditions, respectively, up to $-0.9 \mathrm{MPa}$ e $-0.6 \mathrm{MPa}$. The seed treated with PBZ has the potential of achieve, in water deficit conditions, the final germination similar to that achieve without water deficiency.

Keywords: Water stress; Forage; Germination; Marandú; Pulverization
\end{abstract}

\section{INTRODUÇÃO}

Para a formação de pastagem há a necessidade de sementes de alta qualidade e alto poder de germinação. Contudo as sementes de Urochloa brizantha apresentam desuniformidade na maturação, degrana e dormência, fatores que contribuem para o estabelecimento desuniforme de populações, favorecendo o aparecimento de plantas invasoras por ocasião da semeadura e estágio inicial de desenvolvimento da cultura (SILVA et al., 2014). 
As gramíneas forrageiras são a base da produção animal extensiva e ocupam mais de 170 milhões de hectares no Brasil (IBGE, 2006) onde parte dessa área fornece condições edafoclimáticas adequadas para 0 estabelecimento e crescimento dessas gramíneas, enquanto parte significativa dessa área são consideradas marginais com ocorrências de veranicos, solos arenosos e pobres ou mesmo regiões com períodos prolongados de alagamento (PEZZOPANE et al., 2015). Sendo assim, são necessários estudos sobre tolerância a estas condições ou mesmo tratamentos que permitam mitigar o efeito dos estresses abióticos.

A tecnologia de sementes compreende um conjunto de conhecimentos, especialmente princípios científicos, aplicado ao desenvolvimento de técnicas para fundamentar a produção e utilização de sementes de alta qualidade (MARCOS FILHO, 2015), e o condicionamento osmótico é uma técnica de tratamento pré-semeadura que vem sendo estudado em diversas culturas como uma alternativa para melhorar a uniformidade da germinação e emergência de plântulas.

As diferentes técnicas de hidratação das sementes podem influenciar a resposta ao condicionamento. Em algumas espécies, como alface, a pré-embebição das sementes por 16 horas, não interferiu na germinação, porém influenciou o vigor das plântulas (SOARES et al., 2012). Lopes et al. (2011), trabalhando com sementes de cenoura não condicionadas e condicionadas com água, $\mathrm{KNO}_{3}$ e PEG6000 verificaram que o condicionamento em soluções aeradas de PEG6000 mantém a viabilidade e incrementa $\mathrm{o}$ vigor imediatamente após 0 condicionamento e, em sementes de pimentão não condicionadas e condicionadas com água, $\mathrm{KNO}_{3}$, PEG6000 e $\mathrm{GA}_{3}$, a solução de ácido giberélico aumenta o vigor das sementes.

Bonome et al. (2006), em sementes de Urochloa brizantha condicionadas com PEG 6000, detectaram que o condicionamento osmótico promoveu incremento na velocidade de protrusão radicular. Cardoso et al. (2014), no condicionamento com $\mathrm{KNO}_{3}$, não observaram diferenças entre a germinação e o índice de velocidade de germinação, das sementes condicionadas e não condicionadas de Brachiaria brizantha cv. MG5. Em algumas espécies o condicionamento osmótico pode proporcionar melhorias na viabilidade das sementes, porém em outras não ocorre incrementos, podendo haver redução.

Existe carência de informações acerca de estudos visando melhorar o desempenho de sementes de forrageiras tropicais, principalmente com relação ao uso do paclobutrazol. Muitas pesquisas vêm sendo realizadas sobre o uso do paclobutrazol, derivado dos triazóis, grupo maior e mais importante de compostos sistêmicos, que funcionam como um regulador de crescimento em plantas.

O paclobutrazol vem sendo utilizado para induzir o florescimento e o efeito da aplicação nas plantas tem sido estudado em diversas culturas como em azevém-perene (NAZARI; JAVADI, 2012) abacaxi (ANTUNES et al., 2008), manga (SILVA; NEVES, 2011), feijão (GITTI et al., 2012), porém pouco se conhece sobre seu efeito quando aplicado em sementes. Pill e Gunter (2001), Melo et al. (2014) verificaram efeito negativo do PBZ na germinação de sementes de tomate, no entanto Berova e Zlatev (2003) observaram que o tratamento de sementes com paclobutrazol minimiza os efeitos negativos do estresse hídrico induzido por PEG em triticale, e Baninasab e Ghobadi (2011) verificaram que mudas de pepino oriundas de sementes embebidas com PBZ são mais tolerantes à estresse térmico, portanto novos trabalhos necessitam ser realizados para investigar o efeito do PBZ na aplicação via sementes, tendo em vista que esse produto pode ser promissor em sementes de forrageiras, pois o estresse hídrico é frequente em regiões tropicais.

Diante do exposto, o objetivo do trabalho foi verificar o efeito do pré-tratamento, via pulverização, com paclobutrazol em sementes de Urochloa brizantha cv. Marandú em duas situações, com e sem deficiência de água, sobre a germinação e desenvolvimento inicial das plântulas.

\section{MATERIAL E MÉTODOS}

O experimento foi conduzido no Laboratório de Sementes da Universidade do Oeste Paulista - UNOESTE, localizada em Presidente Prudente - SP, utilizando sementes de Urochloa brizantha cv. Marandú, adquiridas em empresa de sementes da região.

Testes preliminares foram realizados para a verificação de doses de paclobutrazol que seriam utilizadas no experimento. As sementes passaram por um processo de pré-tratamento, sendo expostas de maneira uniforme a uma 
pulverização com 0, 21, 42, 84 e $168 \mathrm{mg} \mathrm{L}^{-1}$ de paclobutrazol (PBZ) na proporção de $10 \mathrm{~mL}$ de solução por quilograma de semente. Após o tratamento as sementes foram colocadas para secar à sombra, em temperatura ambiente $\left(25^{\circ} \mathrm{C} \pm 33^{\circ} \mathrm{C}\right)$, e após a secagem procedeu-se $\mathrm{o}$ teste de germinação.

A germinação por plântulas normais foi conduzida com quatro repetições de 100 sementes, em caixas plásticas transparentes, acondicionadas de forma equidistante, sobre duas folhas de papel para germinação, mantidas em germinador com temperatura alternada de $15-35^{\circ} \mathrm{C}$ e emprego de luz por oito horas na maior temperatura. 0 papel foi embebido em água, na quantidade de 2,5 vezes a sua massa. As contagens foram realizadas aos 7,14 , e 21 dias após a semeadura, computando-se as plântulas normais de acordo com as Regras para Análise de Sementes - RAS (BRASIL, 2009).

A reposição de água foi realizada semanalmente, de acordo com a perda de água da caixa controle. O controle consistia em caixa com duas folhas de papel umedecidas com a quantidade de água equivalente a 2,5 vezes a sua massa, e após a adição de água foi determinada a massa do conjunto caixa-papel-água e uma vez por semana realizava-se a pesagem desse conjunto e a diferença entre o peso inicial e final, em $\mathrm{mL}$, era considerada para reposição de água em todos as caixas com as sementes.

Após o teste de verificação de doses, estabeleceu-se que seriam utilizadas as doses de 0,84 e $168 \mathrm{mg} \mathrm{L}^{-1}$ de paclobutrazol na proporção de $10 \mathrm{~mL}$ de solução por quilograma de semente, pois foi observado que os dados de germinação seguiram um modelo matemático de efeito quadrático, ou seja, a partir da dose calculada de $105 \mathrm{mg} \mathrm{L}^{-1}$ de paclobutrazol iniciou-se um decréscimo na germinação. Com isso optou-se por usar uma dose inferior e uma superior a dose onde a máxima germinação foi obtida. No tratamento sem adição de paclobutrazol as sementes foram pulverizadas com água e levadas para secar conforme descrito anteriormente. Foi adotado também o tratamento denominado testemunha onde as sementes não passaram por nenhum processo de pré-hidratação.

Após a secagem das sementes em temperatura ambiente $(25 \circ \mathrm{C} \pm 3 \circ \mathrm{C})$, estas foram submetidas à germinação em condição de estresse hídrico simulado em laboratório utilizando-se os seguintes níveis de restrição hídrica de 0,-0,3, -0,6 e -0,9 MPa obtidas com soluções de manitol na concentração de $0,22,29$, 44,58 e $66,87 \mathrm{~g} \mathrm{~L}^{-1}$, respectivamente, calculados pela fórmula de Van't Hoff (TAIZ; ZEIGER, 2004).

Germinação em condição de estresse hídrico: foi conduzida conforme descrito acima, porém o papel foi embebido em água ou nas concentrações de manitol, na quantidade de 2,5 vezes a sua massa seca. As caixas plásticas permaneceram envoltas com sacos plásticos para evitar a perda de umidade, e a avaliação foi realizada aos 14 dias após a instalação do teste, computando-se as plântulas normais. O critério adotado para plântulas normais foram os estabelecidos pelas Regras para Análise de Sementes (BRASIL, 2009).

Posteriormente foi realizada a germinação por protrusão de raiz, seguindo a mesma metodologia descrita para a germinação em condição de estresse hídrico, porém as sementes foram submetidas à germinação em condição de estresse hídrico utilizando-se os seguintes níveis de potencial osmóticos de 0 , $0,3,-0,6$ e $-1,2 \mathrm{MPa}$ obtidas com soluções de manitol na concentração de $0,22,29,44,58$ e $89,17 \mathrm{~g} \mathrm{~L}^{-1}$, respectivamente, calculados pela fórmula Van't Hoff (TAIZ; ZEIGER, 2004).

A contagem da germinação por protrusão de raiz foi iniciada a partir do 4 o dia, quando observou protrusão mínima de $2 \mathrm{~mm}$, e posteriormente a cada 2 dias computando-se as sementes que haviam emitido raiz até atingir 21 dias após a semeadura. A reposição de água foi realizada semanalmente, de acordo com a perda de água da caixa controle conforme descrito anteriormente.

Índice de velocidade de germinação por protrusão de raiz (IVG): foi conduzido junto com o teste de germinação por protrusão de raiz e as avaliações foram realizadas a cada 2 dias, dividindo o número de sementes com protrusão de raiz pelo número de dias decorridos entre a semeadura e a contagem (MAGUIRE et al., 1962).

Procedimento estatístico: o estudo de doses foi conduzido em delineamento inteiramente casualizado, com quatro repetições, com aplicação da regressão polinomial. Quando indicado resultado significativo pela análise de variância $(p \leq 0,05)$ para a germinação em condição de estresse hídrico e $(p \leq 0,10)$ para germinação por protrusão e índice de velocidade de germinação por protrusão de raiz, os tratamentos de sementes foram comparados pelo teste Tukey, e os níveis de potencial osmótico foram avaliados por equações de 
regressão polinomial à $5 \%$ e $10 \%$ de probabilidade, adotando o maior coeficiente de determinação $\left(R^{2}\right)$, utilizando o programa estatístico SISVAR (FERREIRA, 2011). Na germinação acumulada foi calculada a média e o desvio padrão para cada tratamento de sementes e níveis de potencial osmótico.

\section{RESULTADOS E DISCUSSÃO}

No estudo preliminar para definir a dose de PBZ a ser utilizada nesse experimento, verificou-se que os dados de germinação ajustaram-se a um modelo quadrático (Figura 1), sendo o ponto de máxima germinação estimada na dose de $105 \mathrm{mg} \mathrm{L}^{-1}$, com redução na germinação a partir desta dose. Diante deste resultado optou-se por adotar as doses de $84 \mathrm{e}$ $168 \mathrm{mg} \mathrm{L}^{-1}$. E para o índice de velocidade de germinação de plântulas normais não foi observado diferenças significativas.

Melo et al. (2014) afirmam que altas concentrações de PBZ mostram-se prejudiciais as porcentagens e velocidades de germinação e emergência de plântulas, corroborando com o observado no estudo preliminar de doses para germinação, pois a partir da dose estimada de $105 \mathrm{mg} \mathrm{L}^{-1}$ de paclobutrazol há uma redução na germinação das sementes.

Pasian e Bennett (2001) afirmam que pode ocorrer uma migração do produto aderido ao tegumento para regiões meristemáticas da semente. Os mesmos relatam que no substrato usado para germinação em laboratório, a concentração do regulador pode chegar a níveis inibitórios, prejudicando a germinação, em altas concentrações, o que pode ter ocorrido no estudo de doses (Figura 1).

Figura 1. Estudo de doses de paclobutrazol (PBZ) para germinação de sementes de Urochloa brizantha cv. Marandú.

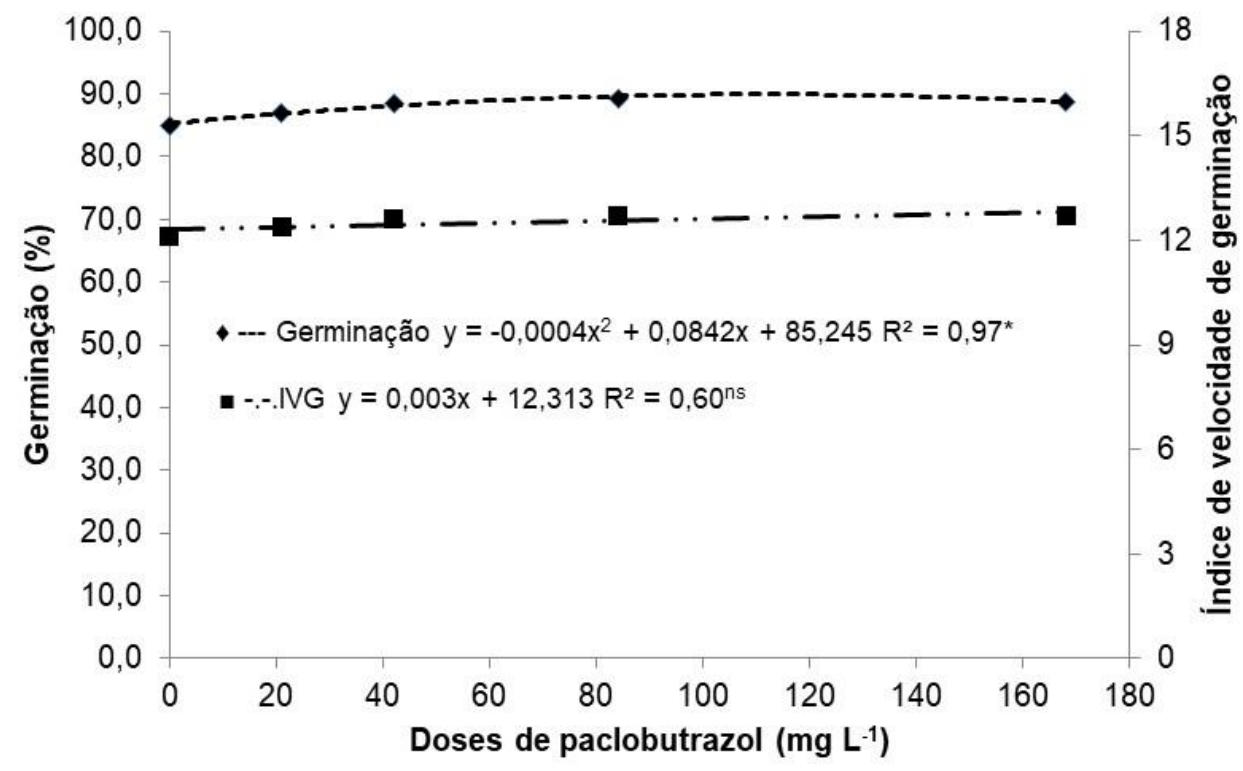

No teste de germinação em condição de estresse hídrico, avaliado aos 14 dias verificou-se interação entre o tratamento de sementes e os níveis de potencial osmótico (Tabela 1), e no desdobramento da interação observou-se um ajuste linear decrescente para todos os prétratamento de sementes (Tabela 2).

Ao analisar os tratamentos de sementes dentro de cada potencial osmótico verificou-se que não houve diferença na germinação para os tratamentos, sem restrição e com $-0,3 \mathrm{MPa}$, já no potencial de $-0,6 \mathrm{MPa}$ a semente tratada com PBZ na dose de $84 \mathrm{mg} \mathrm{L}^{-1}$ apresentou maior germinação em relação a semente tratada com PBZ 0 (água pura) e PBZ 168 (168 $\left.\mathrm{mg} \mathrm{L}^{-1}\right)$. E no potencial de $-0,9 \mathrm{MPa}$ os tratamentos que diferiram estatisticamente foram semente seca e semente tratada com PBZ na dose de $168 \mathrm{mg} \mathrm{L}^{-1}$ com maior germinação no tratamento com PBZ (Tabela 2). 
Tabela 1. Germinação por plântulas normais de sementes de Urochloa brizantha cv. Marandú, submetidas a diferentes pré-tratamentos das sementes e potencial osmótico. Presidente Prudente/SP, 2014

\begin{tabular}{lc}
\hline Tratamento & Germinação \\
\hline Pré-tratamento das sementes (A) & 71 \\
Semente Seca & 74 \\
PBZ $0 \mathrm{mg} \mathrm{L}^{-1}$ de paclobutrazol (água) & 75 \\
PBZ $84 \mathrm{mg} \mathrm{L}^{-1}$ de paclobutrazol & 71 \\
PBZ $168 \mathrm{mg} \mathrm{L}^{-1}$ de paclobutrazol &
\end{tabular}

\section{Potencial osmótico (MPa) (B)}

0

$-0,3$

86

$-0,6$

85

$-0,9$

49

\section{Valor de $\mathrm{F}$}

Pré-tratamento (A)

Potencial osmótico (B)

$1,95^{\text {ns }}$

$\mathrm{A} \times \mathrm{B}$

$153,250^{* *}$

$3,122 * *$

Médias seguidas de letras distintas diferem entre si pelo teste de Tukey a $5 \%$ de probabilidade. ns e ** são: não significativo e significativo a $1 \%$ de probabilidade pelo teste $\mathrm{F}$.

Tabela 2. Desdobramento da interação pré-tratamento de sementes e potencial osmótico para germinação por plântulas normais de sementes de Urochloa brizantha cv. Marandú. Presidente Prudente/SP, 2014

\begin{tabular}{lcccccc} 
Pré-tratamento & \multicolumn{4}{c}{ Potencial osmótico (MPa) } & \multicolumn{2}{c}{ Equação } \\
\cline { 2 - 5 } & 0 & $-0,3$ & $-0,6$ & $-0,9$ & & \\
\hline Semente seca & $87 \mathrm{a}$ & $83 \mathrm{a}$ & $72 \mathrm{ab}$ & $43 \mathrm{~b}$ & $\mathrm{y}=47,92 \mathrm{x}+93,0$ & $\mathrm{R}^{2}=86^{* *}$ \\
PBZ 0 (água) & $85 \mathrm{a}$ & $90 \mathrm{a}$ & $67 \mathrm{~b}$ & $52 \mathrm{ab}$ & $\mathrm{y}=92,07 \mathrm{x}+41,00 \mathrm{R}^{2}=83^{* *}$ \\
PBZ 84 & $88 \mathrm{a}$ & $85 \mathrm{a}$ & $79 \mathrm{a}$ & $47 \mathrm{ab}$ & $\mathrm{y}=42,75 \mathrm{x}+94,43$ & $\mathrm{R}^{2}=77^{* *}$ \\
PBZ 168 & $83 \mathrm{a}$ & $81 \mathrm{a}$ & $65 \mathrm{~b}$ & $54 \mathrm{a}$ & $\mathrm{y}=34,5 \mathrm{x}+86,7$ & $\mathrm{R}^{2}=93^{* *}$ \\
\hline
\end{tabular}

Médias seguidas de letras distintas, na coluna, diferem entre si pelo teste de Tukey a $5 \%$ de probabilidade. ${ }^{* *}$ : significativo a $1 \%$ de probabilidade pelo teste $\mathrm{F}$.

Souza et al. (2010) trabalhando com clormequat, paclobutrazol, trinexapac-etil, que são reguladores de crescimento que atuam na síntese de giberelina, observaram que a germinação e o vigor (primeira contagem, emergência em campo e envelhecimento acelerado) de sementes de trigo não foram afetadas nas doses estudadas. No entanto, Pill e Gunter (2001), avaliando o efeito do paclobutrazol em semente de tomate, verificaram efeitos prejudiciais para a germinação das sementes e na emissão de plântulas devido ao efeito antigiberelina no embrião.

O déficit hídrico é um dos principais limitadores de germinação, pois cada espécie apresenta um valor de potencial hídrico abaixo do qual a germinação não ocorre, e neste estudo verificou-se que, independente do prétratamento das sementes, com -0,6 MPa há redução na germinação, e esta diminui à medida que aumenta a restrição hídrica, portanto os tratamentos de sementes alteraram a resposta da semente em relação à restrição de água, com vantagens na germinação quando as sementes receberam PBZ no pré-tratamento. A tendência de uma semente germinar em ambiente desfavorável pode ser uma demonstração de alto vigor, como, por exemplo, em época de seca prolongada, onde seu vigor pode apresentar competitividade no meio (MARCOS FILHO, 2015).

Foi observado, em estudos realizados, que a germinação foi reduzida a partir do potencial osmótico de $-0,15 \mathrm{MPa}$ no substrato em sementes de Conyza canadensis e Conyza bonariensis (buva) (YAMASHITA; GUIMARÃES, 2010), e -0,4 MPa em sementes de Urochloa ruziziensis (MASETTO et al., 2013).

Quando o potencial osmótico da solução é menor em relação aos da célula do embrião, ocorre uma queda na velocidade e porcentagem de germinação, decorrente da diminuição de entrada de água, acarretando uma deficiência no acúmulo de energia necessária para emissão de raiz (MARCOS FILHO, 2015). 
No teste de germinação por protrusão de raiz, verificou-se interação entre os tratamentos de sementes e os níveis de potencial osmótico (Tabela 3), e no desdobramento da interação houve um ajuste linear para semente seca e PBZ
84, porém para semente PBZ 0 (água pura) e PBZ 168 houve um ajuste quadrático tendo máxima germinação, no potencial calculado de -0,23 e 0,27 MPa, respectivamente (Tabela 4).

Tabela 3. Germinação por protrusão de raiz (GPR) e índice de velocidade de germinação (IVG) de sementes de Urochloa brizantha cv. Marandú, submetidas a diferentes pré-tratamento de sementes e potencial osmótico. Presidente Prudente/SP, 2014

\begin{tabular}{|c|c|c|}
\hline TRATAMENTO & GPR & IVG \\
\hline \multicolumn{3}{|l|}{ Pré-tratamento das sementes (A) } \\
\hline Semente seca & 73 & 14,0 \\
\hline PBZ $0 \mathrm{mg} \mathrm{L}^{-1}$ de paclobutrazol (água) & 73 & 14,0 \\
\hline PBZ $84 \mathrm{mg} \mathrm{L}^{-1}$ de paclobutrazol & 74 & 14,7 \\
\hline PBZ $168 \mathrm{mg} \mathrm{L}^{-1}$ de paclobutrazol & 75 & 15,4 \\
\hline \multicolumn{3}{|l|}{ Potencial osmótico (MPa) } \\
\hline 0 & 87 & 19,5 \\
\hline$-0,3$ & 89 & 18,5 \\
\hline$-0,6$ & 80 & 14,6 \\
\hline$-1,2$ & 38 & 5,5 \\
\hline \multicolumn{3}{|c|}{ VALOR DE F } \\
\hline Pré-tratamento $(\mathrm{A})$ & $0,525^{\mathrm{ns}}$ & $6,065^{* *}$ \\
\hline Potencial (B) & $359,107 * *$ & $533,883 * *$ \\
\hline$A \times B$ & $1,962 *$ & $6,508^{* *}$ \\
\hline
\end{tabular}

Médias seguidas de letras distintas diferem entre si pelo teste de Tukey a $10 \%$ de probabilidade. ns e ** são: não significativo e significativo a $1 \%$ de probabilidade pelo teste $\mathrm{F}$.

Avaliando o desdobramento para cada potencial osmótico verificou-se diferença entre os tratamentos de sementes apenas no potencial de $-0,6 \mathrm{MPa}$ onde a semente seca diferiu das sementes tratadas com PBZ na dose de 84 e 168 $\mathrm{mg} \mathrm{L}^{-1}$, com maior germinação nos tratamentos com paclobutrazol (Tabela 4).

O melhor resultado observado nas sementes tratadas com PBZ pode estar relacionado à atividade das enzimas nitrato redutase e glutamina sintase, pois Dwivedi et al.
(2012) estudando a produção de trigo verificaram que a condição de estresse hídrico leva à diminuição da atividade de duas enzimas principais da via de assimilação de $\mathrm{N}$, ou seja, nitrato redutase e glutamina sintetase e que com a aplicação de citocinina, paclobutrazol e ácido ascórbico, em combinação, aumentou a atividade de ambas as enzimas nos cultivares HD 2733 e HD 2987 em condições de déficit hídrico.

Tabela 4. Desdobramento da interação tratamento de sementes e potencial osmótico por protrusão de raiz de sementes de Urochloa brizantha cv. Marandú. Presidente Prudente/SP, 2014

\begin{tabular}{|c|c|c|c|c|c|}
\hline \multirow[t]{2}{*}{ Pré-tratamento } & \multicolumn{4}{|c|}{ Potencial osmótico (MPa) } & \multirow[t]{2}{*}{ Equação } \\
\hline & 0 & $-0,3$ & $-0,6$ & $-1,2$ & \\
\hline Pré-tratamento & \multicolumn{4}{|c|}{ 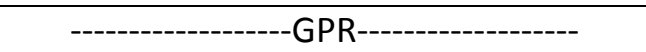 } & \\
\hline Semente seca & $91 \mathrm{a}$ & $92 \mathrm{a}$ & $73 \mathrm{~b}$ & $35 \mathrm{a}$ & $y=49,88 x+99 R^{2}=92,01 * *$ \\
\hline PBZ 0 (água) & $86 a$ & $88 \mathrm{a}$ & $81 a b$ & $38 \mathrm{a}$ & $y=-53,28 x^{2}-23,98 x+85,71 R^{2}=100 * *$ \\
\hline PBZ 84 & $87 a$ & $87 \mathrm{a}$ & $82 \mathrm{a}$ & $39 a$ & $y=41,6 x+95,65 R^{2}=83,5^{* *}$ \\
\hline PBZ 168 & $86 a$ & $88 \mathrm{a}$ & $84 \mathrm{a}$ & $41 \mathrm{a}$ & $y=-54,99 x^{2}-29,25 x+85,5 R^{2}=99,8^{* *}$ \\
\hline Pré-tratamento & \multicolumn{4}{|c|}{-------------------IVG----------------- } & \\
\hline Semente seca & $19,7 \mathrm{a}$ & 19,6 a & $11,4 \mathrm{c}$ & 5,4 a & $y=12,99 x+20,84 R^{2}=92,35 * *$ \\
\hline PBZ 0 (água) & 19,9 a & $16,8 \mathrm{~b}$ & $14,3 \mathrm{~b}$ & $5,0 \mathrm{a}$ & $y=12,37 x+20,46 R^{2}=98,16 * *$ \\
\hline PBZ 84 & $19,5 \mathrm{a}$ & 18,9 a & $17,2 \mathrm{a}$ & $6,2 \mathrm{a}$ & $y=11,46 x+21,44 R^{2}=88,34^{* *}$ \\
\hline PBZ 168 & $19,0 \mathrm{a}$ & $18,9 \mathrm{a}$ & $15,5 \mathrm{ab}$ & $5,3 \mathrm{a}$ & $y=12,13 x+21,04 R^{2}=91,5^{* *}$ \\
\hline
\end{tabular}


Médias seguidas de letras distintas, na coluna, diferem entre si pelo teste de Tukey a $10 \%$ de probabilidade. ${ }^{* *}$ : significativo a $1 \%$ de probabilidade pelo teste $\mathrm{F}$.

Para o IVG houve interação entre os tratamentos (Tabela 3), e na análise do desdobramento verificou-se efeito linear decrescente em todos os pré-tratamento de sementes, e ao avaliar o IVG em cada potencial osmótico constatou-se diferença entre os tratamentos no potencial -0,3 e -0,6 MPa, sendo que no potencial $-0,3 \mathrm{MPa}$ a semente tratada com PBZ 0 (água pura) apresentou o menor índice e diferiu dos demais, e no potencial -0,6 $\mathrm{MPa}$ a semente seca diferiu dos demais tratamentos, onde observou-se o menor índice (Tabela 4).

O pré-tratamento com pulverização das soluções, pode ter favorecido a germinação das sementes, pois de acordo com Bewley et al. (2012), após o condicionamento fisiológico, as sementes estarão praticamente no mesmo estádio metabólico e, consequentemente, a germinação ocorrerá de forma rápida e sincronizada.

Pereira et al. (2012), observaram em Urochloa decumbens e Urochloa ruziziensis que estresse hídrico e a salinidade afetam a germinação e o índice de velocidade de germinação das sementes e os prejuízos são proporcionais à redução do potencial osmótico, com germinação praticamente nula no potencial 0,8 MPa. Masetto et al. (2013), trabalhando com sementes de $U$. ruziziensis verificaram que a germinação foi afetada negativamente com a redução dos potenciais hídricos até -0,4 $\mathrm{MPa}$. Custódio et al. (2011), trabalhando com sementes intactas e peliculizadas de Brachiaria brizantha cv. Marandú observaram germinação inferior a $10 \%$ no potencial $-0,9 \mathrm{MPa}$ e ausência total de germinação na restrição -1,2 $\mathrm{MPa}$.

Diferente do observado no presente estudo, pois no potencial com maior restrição (1,2 MPa) ainda observou-se germinação, a qual variou de 30 a $41 \%$ em função dos diferentes prétratamento de sementes. A restrição hídrica pode reduzir a velocidade de germinação (IVG), e a porcentagem de germinação, à medida que o potencial osmótico diminui, há também uma diminuição dos processos metabólicos e bioquímicos, o que interfere no alongamento celular, prejudicando a germinação (MARCOS FILHO, 2015).

Ao analisar a germinação acumulada em cada pré-tratamento de sementes nos diferentes níveis de potencial osmótico, observa-se que para semente seca a germinação no potencial 0 e -0,3 $\mathrm{MPa}$ foram semelhantes desde o início da germinação, com valores próximo a $80 \%$. E quando a semente recebeu pré-tratamento com água (PBZ 0) houve um incremento na germinação, atingindo germinação final próxima as das sementes germinadas nos menores potenciais osmóticos (Figura 2A e 2B).

Quando a semente foi tratada com PBZ 84 e $168 \mathrm{mg} \mathrm{L}^{-1}$ de paclobutrazol, mesmo em condição de restrição hídrica mais elevada $(-0,6$ $\mathrm{MPa})$, a semente tem potencial para alcançar a germinação final semelhante à germinação de uma semente na ausência de restrição hídrica (Figura 2C e 2D). 
Figura 2. Germinação acumulada por protrusão de raiz de sementes de Urochloa brizantha cv. Marandú, submetidas ao pré-tratamento: semente seca $(A)$, semente tratada com PBZ $0 \mathrm{mg} \mathrm{L}^{-1}$ de paclobutrazol (água pura) (B), semente tratada com PBZ $84 \mathrm{mg} \mathrm{L}^{-1}$ de paclobutrazol (C) e semente tratada com PBZ 168 $\mathrm{mg} \mathrm{L}^{-1}$ de paclobutrazol (D) em diferentes potenciais hídricos. Presidente Prudente/SP, 2014
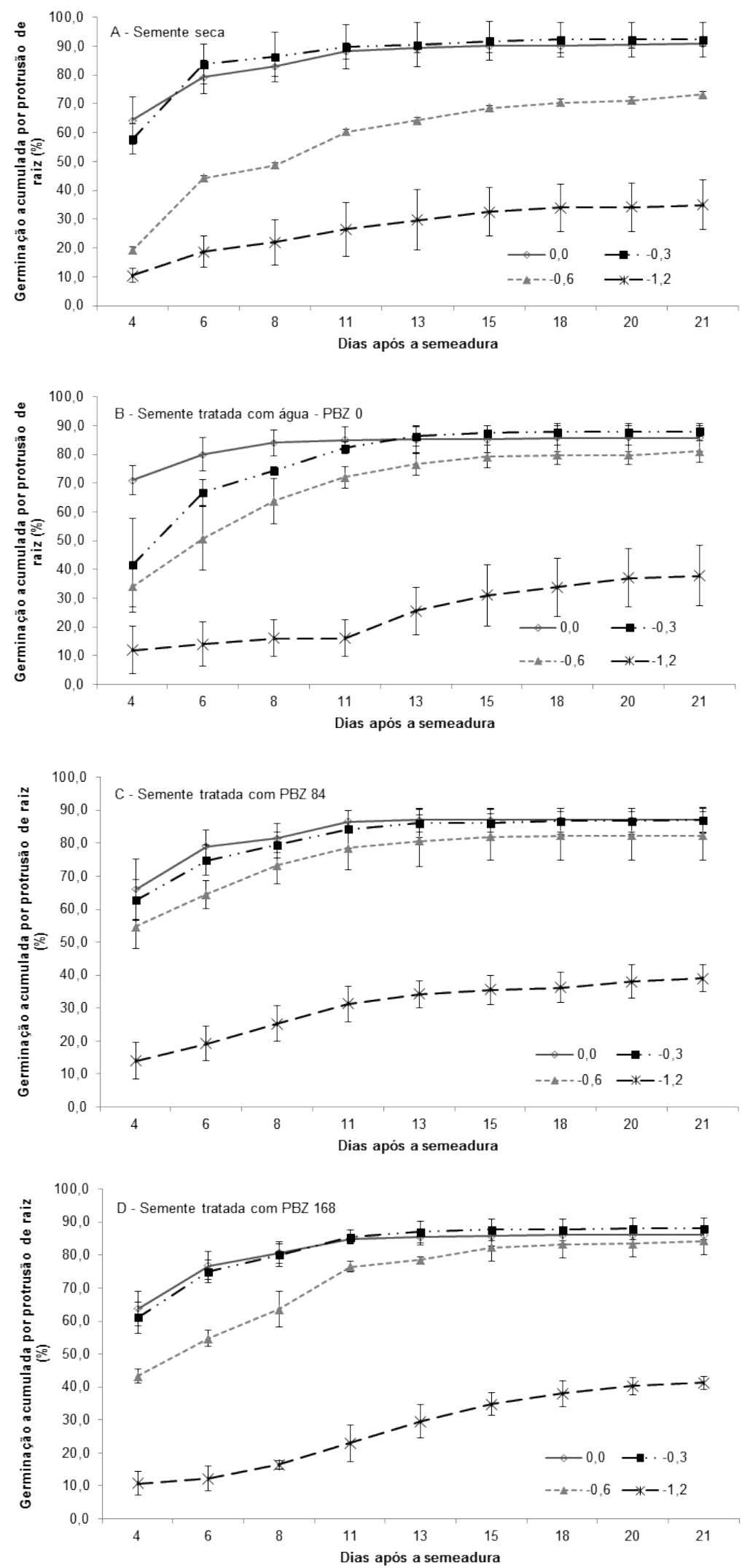
No potencial 0 e -0,3 MPa o desempenho das sementes foram semelhantes, independente do tratamento empregado nas sementes (Figura $3 \mathrm{~A}$ e $3 \mathrm{~B}$ ), mas em condições de restrição mais elevada, ou seja, -0,6 MPa as sementes hidratadas com água e com PBZ tiveram uma germinação inicial maior quando comparadas à sementes seca, embora esta tenha alcançado germinação final semelhantes as demais (Figura $3 C)$.

A germinação acumulada por protrusão de raiz da semente tratada com PBZ 84 foi semelhante à semente seca, porém o início da germinação quando a semente foi tratada com PBZ é aproximadamente $50 \%$ superior à semente seca (Figura 3C).

Esses resultados indicam que 0 paclobutrazol pode ser um produto promissor para melhorar o desempenho de forrageiras tropicais em condições de estresse hídrico, pois demonstram que as sementes tratadas com esse produto mostram-se mais tolerantes as condições de estresse hídrico o que pode estar relacionada a mudanças na taxa fotossintética líquida e taxa de transpiração, pois Berova e Zlatev (2003) verificaram que a taxa fotossintética líquida, a taxa de transpiração, a condutância estomática, o teor relativo de água e o potencial hídrico foliar foram maiores, enquanto a atividade da peroxidase e a concentração livre de prolina foram menores nas plantas provenientes de sementes tratadas com paclobutrazol do que nas plantas controle.

Plantas tolerantes à estresse com uso de PBZ também foi verificado por Baninasab e Ghobadi (2011), avaliando o efeito do paclobutrazol via tratamento de sementes e aplicação foliar em mudas de pepino, quando constataram que, independentemente do modo de aplicação, a utilização do PBZ conferiu proteção parcial às mudas de pepino contra estresse por alta temperatura, prevenindo perdas de colheitas.

No potencial osmótico -1,2 MPa, ou seja, com maior restrição hídrica (Figura 3D) em todos os tratamentos de sementes ocorreu uma baixa germinação acumulada por protrusão de raiz. A ausência de resposta do tratamento está relacionada ao nível acentuado de restrição hídrica, pois de acordo com Bewley et al. (2012), a inibição da protrusão da raiz primária decorrente de um potencial osmótico mais acentuado, tem relação com a redução de atividades enzimáticas, gerando prejuízos no desenvolvimento germinativo das sementes.

Verificou-se que as sementes submetidas à restrição hídrica mais acentuada simulada pela solução de manitol, responderam de forma negativa, diminuindo o IVG e a porcentagem de germinação. As sementes colocadas para germinar em solução de água destilada (Figura $3 \mathrm{~A})$, germinaram mais que as mantidas em solução de manitol de -0,6 e -1,2 MPa. Resultados semelhantes foram encontrados por Christovam et al. (2015), em sementes de Urochloa brizantha cv. MG4, MG5, Marandú e Piatã.

Silva et al. (2012), estudando diferentes concentrações de PEG 6000 na germinação de semente de arroz, verificou que o processo de germinação em potencial osmótico abaixo de -0,2 $\mathrm{MPa}$, a absorção de água é limitada, ocasionando o retardamento no processo germinativo. Resultados semelhantes podem ser notados no presente trabalho (Figura $3 \mathrm{~A}$ a $3 \mathrm{D}$ ), onde a porcentagem de germinação final é reduzida à medida que aumenta a concentração de manitol e consequentemente, diminui a disponibilidade de água.

A disponibilidade de água está relacionada diretamente com a germinação, pois sua absorção resultará na reidratação dos tecidos, aumento da respiração e da atividade metabólica, que fornecerá energia necessária para a retomada do crescimento do eixo embrionário (MARCOS FILHO, 2015).

À medida que a quantidade de água decresce, ocorre a diminuição do potencial hídrico do substrato em que se encontra a semente. Com isso a absorção de água, pela semente, é dificultada, e dependendo do potencial hídrico da matriz pode não ocorrer absorção pela semente (TAIZ; ZEIGER, 2004). Tal fato, explica a diminuição da germinação acumulada (Figura 3D), pois o potencial hídrico gerado pelo manitol no substrato foi menor do que apresentava a semente, fazendo com que esta não conseguisse absorver água. 
Figura 3. Germinação acumulada por protrusão de raiz de sementes de Urochloa brizantha cv. Marandú, no potencial hídrico $0 \mathrm{MPa}(\mathrm{A}),-0,3 \mathrm{MPa}(\mathrm{B}),-0,6 \mathrm{MPa}$ (C) e -1,2 $\mathrm{MPa}(\mathrm{D})$, submetidas a diferentes prétratamento de sementes. Presidente Prudente/SP, 2014
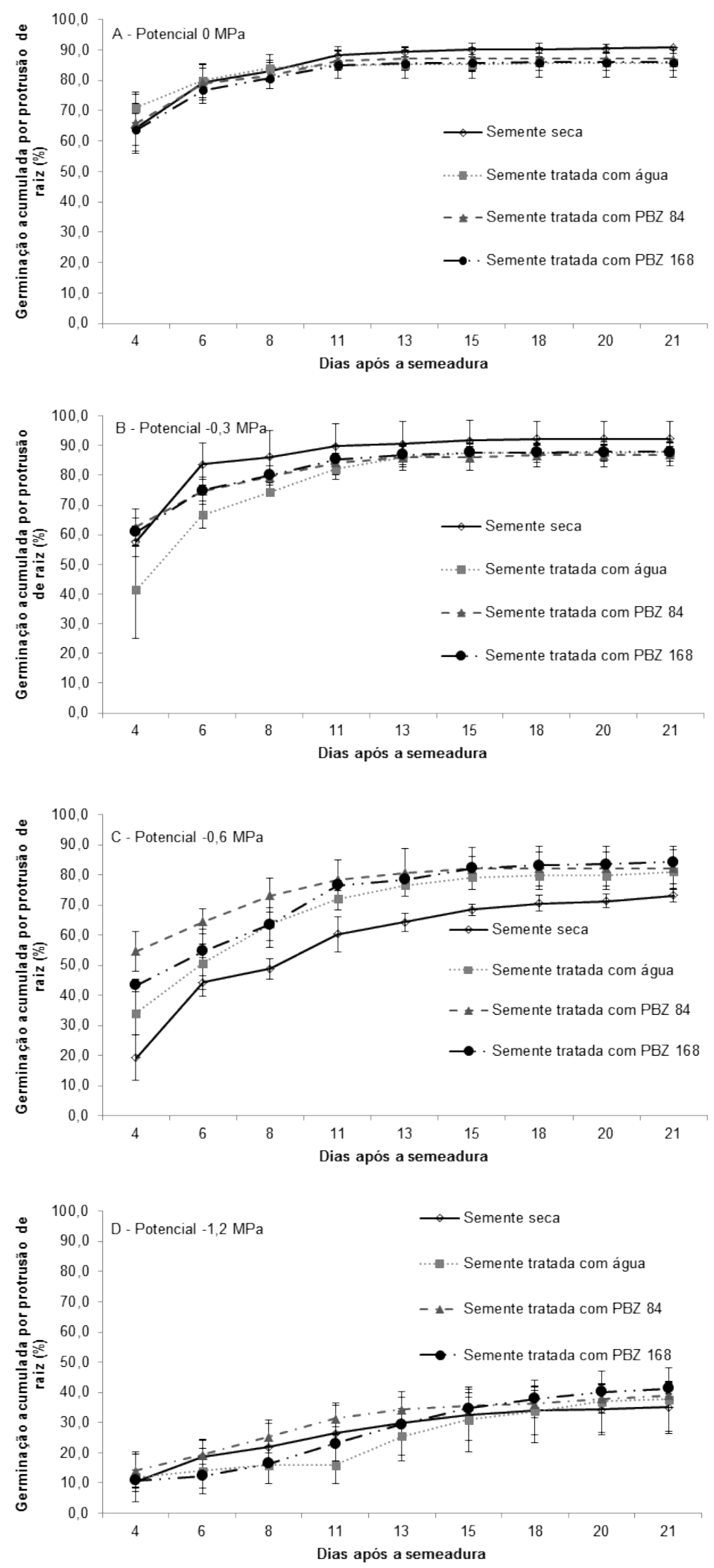


\section{CONCLUSÃO}

A máxima germinação em condições normais é encontrada na dose de $105 \mathrm{mg} \mathrm{L}^{-1}$ de PBZ.

A restrição hídrica reduz a germinação das sementes por plântulas normais e protrusão de raiz.

O pré-tratamento das sementes favorece a germinação por plântulas normais e protrusão de raiz em condição de restrição hídrica, respectivamente, até $-0,9 \mathrm{MPa}$ e $-0,6 \mathrm{MPa}$.

A semente tratada com paclobutrazol tem potencial para alcançar, em condição de restrição hídrica, a germinação final semelhante à germinação na ausência de restrição hídrica.

A germinação acumulada inicial da semente tratada com paclobutrazol é mais elevada quando comparada à semente seca.

\section{REFERÊNCIAS}

ANTUNES, A.N; ONO, E.O; SAMPAIO, A.C. Efeito do paclobutrazol no controle da diferenciação floral natural do abacaxizeiro cv. smooth cayenne. Revista Brasileira Fruticultura, v.30, p.290-295, 2008. https://doi.org/10.1590/S0100$\underline{29452008000200004}$

BANINASAB, B.; GHOBADI, C. Influence of Paclobutrazol and Application Methods on Hightemperature Stress Injury in Cucumber Seedlings. Plant Growth Regulation, v.30, p.213219, 2011. http://link.springer.com/article/10.1007/s00344010-9188-2. https://doi.org/10.1007/s00344$\underline{010-9188-2}$

BEROVA, M.; ZLATEV, Z. Physiological Response of Paclobutrazol-Treated Triticale Plants to Water Stress. Biologia Plantarum, v.46, n.1, p.133-136, 2003.

\section{https://doi.org/10.1023/A:1022360809008}

BEWLEY, J.D.; BRADFORD, K.J.; HILHORST, H.W.M.; NONOGAKI, H. Seeds: physiology of development, germination and dormancy. 3ed. Springer Science \& Business Media, New York, USA. 392 p., 2012.

BONOME, L.T.S.; GUIMARÃES, R.M.; OLIVEIRA, J.A.; ANDRADE, V.C.; CABRAL, P.S. Efeito do condicionamento osmótico em sementes de Brachiaria brizantha cv. Marandú. Ciências e Agrotecnologia, v.30, p.422-428, 2006.
https://doi.org/10.1590/S1413-

$\underline{70542006000300006}$

BRASIL. Ministério da Agricultura, Pecuária e Abastecimento. Regras para análise de sementes. Ministério da Agricultura, Pecuária e Abastecimento. Secretaria de Defesa Agropecuária. MAPA/ACS, Brasília, Brasil. 395 p., 2009.

CARDOSO, E.D.; SÁ, M.E. DE.; HAGA, K.I.; BINOTTI, F.F.S.; NOGUEIRA, D.C.; VALÉRIO FILHO, W.V. Desempenho fisiológico e superação de dormência em sementes de Brachiaria brizantha submetidas a tratamento químico e envelhecimento artificial. Semina: Ciências Agrárias, v.35, p.21-38, 2014. https://doi.org/10.5433/1679$\underline{0359.2014 v 35 n 1 p 21}$

CHRISTOVAM, M.C., SILVA, T.L. DA.; YAMAMOTO, C.J.T. MOREIRA, A.L.L., CUSTÓDIO, C.C.; PACHECO, A.C.; ABRANTES, F.L. Germinação e desenvolvimento inicial de plântulas de cultivares de Urochloa brizantha em condições de estresse hídrico. Informativo Abrates, v.25, p.43-49, 2015. http://www.abrates.org.br/informativo/artigospublicados/1267-informativo-abrates-volume-25numero-1-2015

CUSTÓDIO, C.C. AMBIEL, A.C., RODRIGUES, D.Z., AGOSTINI, E.A.T., FACTUR, V.D., PAVANELLI, L.E. Peliculização de sementes não revestidas e escarificadas de Urochloa brizantha (HOCHST. Ex a. Rich.) Stapf. Pesquisa Agropecuária Tropical, v.41, p.314-321, 2011. http://www.revistas.ufg.br/index.php/pat/article /view/9146

https://doi.org/10.5216/pat.v41i3.9146

DWIVEDI, S.K.; SINGH, V.P.; SINGH, G.P.; ARORA, A. Combined effect of cytokinin, paclobutrazol and ascorbic acid on nitrogen metabolism and yield of wheat (Triticum aestivum L.) under water deficit stress condition. Indian Journal Plant Physiolgy, v.17, n.3-4, p.259-267, 2012.

FERREIRA, D. F. Sisvar: um sistema computacional de análise estatística. Ciência e Agrotecnologia, v.35, p.1039-1042, 2011. http://www.scielo.br/scielo.php?script=sci_arttex t\&pid=S1413-

$70542011000600001 \& \operatorname{lng}=e n \& n r m=$ iso 
https://doi.org/10.1590/S1413-

$\underline{70542011000600001}$

GITTI, D.C.; ARF, O.; BUZETTI, S.; FERREIRA, M.M.R.; KAPPES, C.; KANEKO, F.H.; RODRIGUES, R.A.F. Aplicação de paclobutrazol e doses de nitrogênio em feijão de inverno cultivado em sistema plantio direto. Scientia Agraria Paranaensis, v.11, p.35-46, 2012. https://doi.org/10.18188/1983-

1471/sap.v11n3p35-46

IBGE (INSTITUTO BRASILEIRO DE GEOGRAFIA E ESTATÍSTICA), 2006. Disponível em: <http://www.ibge.gov.br>. Acesso em: $14 \mathrm{de}$ agosto de 2017.

LOPES, H.M.; MENEZES, B.R.S.; SILVA, E.R. DA.; RODRIGUES, D.L. Condicionamento fisiológico de sementes de cenoura e pimentão. Revista Brasileira de Agrociência, v.17, p.296-302, 2011. http://www2.ufpel.edu.br/faem/agrociencia/v17 n3/artigo02.pdf

MAGUIRE, J. D. Speeds of germination-aid selection and evaluation or seedling emergence and vigor. Crop Science, v.2, p.176-177, 1962. https://doi.org/10.2135/cropsci1962.0011183X0 $\underline{00200020033 x}$

MARCOS FILHO, J. Fisiologia de sementes de plantas cultivadas. 2ed. Fealq, Piracicaba, Brasil, 659p., 2015. https://doi.org/10.2135/cropsci1962.0011183X0 $\underline{00200020033 x}$

MASETTO, T.E.; RIBEIRO, D.M.; REZENDE, R.K.S. Germinação de sementes de Urochloa ruziziensis em função da disponibilidade hídrica do substrato e teor de água das sementes. Pesquisa Agropecuária Tropical, v.43, p.385-391. 2013. https://doi.org/10.1590/S1983-

40632013000400010

MELO, P.C.A.; SELEGUINI, A.; VELOSO, R.S.V. Peliculização de sementes de tomate associada ao paclobutrazol. Bragantia, v.73, p.123-129, 2014. https://doi.org/10.1590/brag.2014.026

NAZARI, F.; JAVADI, T. Growth and Development of Lolium perenne L. 'Barbal' in Response to different concentrations of Paclobutrazol. Journal of Biodiversity and Environmental Sciences, v.6, n.17, p.195-198, 2012. http://deu.dergipark.gov.tr/jbes/issue/16113/16 8625

PASIAN, C.C.; BENNETT, M. Paclobutrazol soaked marigold, geranium, and tomato seeds produce short seedlings. HortScience, v.36, p.721-731, 2001.

http://hortsci.ashspublications.org/content/36/4 /721.full.pdf+html

PEREIRA, M.R.R.; MARTINS, C.C.; SOUZA, G.S.F. DE.; MARTINS, D. Influência do estresse hídrico e salino na germinação de Urochloa decumbens e Urochloa ruziziensis. Bioscience Journal, v.28, p.537-545, 2012. http://www.seer.ufu.br/index.php/biosciencejou rnal/article/view/13447/9743

PEZZOPANE, C. G., SANTOS, P. M., CRUZ, P. G., ALTOÉ, J., RIBEIRO, F. A., VALLE, C. B. Estresse por deficiência hídrica em genótipos de Brachiaria brizantha. Ciência Rural, v.45, n.5, p. 871-876, 2015. https://doi.org/10.1590/0103-

$\underline{8478 \mathrm{cr} 20130915}$

PILL, W.G.; GUNTER, J.A. Emergence and shoot growth of cosmos and marigold from paclobutrazol-treated seed. Journal of Environmental Horticulture, v.19, p.11-14. 2001. https://www.researchgate.net/publication/2648 41150_Emergence_and_Shoot_Growth_of_Cosm os_and_Marigold_from_Paclobutrazol-

treated_Seed_1?enrichld=rgreq6f823c3496514f0d414749338a38d85fXXX\&enrichSource=Y292ZXJQYWdIOzI2NDgOMTE 1MDtBUzoxNTcyMTM1NTMzNDAOMTdAMTQxN DQ5NDA0MDYOMA\%3D\%3D\&el=1_x_2

SILVA, A.L.M.S.; TORRES, F.E.; GARCIA, L.L.P.; MATTOS, E.M.; TEODORO, P.E. Tratamentos para quebra de dormência em Brachiaria brizantha. Revista de Ciências Agrárias, v.37, p.37-41, 2014. http://www.scielo.mec.pt/scielo.php?script=sci_a rttext\&pid=S0871-018X2014000100006

SILVA, J. A. L; NEVES, J.A. Combinação do paclobutrazol, sulfato de potássio e etefon na indução floral da mangueira cv. Tommy Atkins. Comunicata Scientiae, v.2, p.18-24, 2011. https://comunicatascientiae.com.br/comunicata/ article/view/23/55

SILVA, L.S.; SILVA, R.B.; VALADARES, R.N.; MATOS, V.P.; LIMA, C.F. Comportamento de semente de 
arroz sob diferentes potenciais osmóticos. Revista Trópica - Ciências Agrárias e Biológicas, v.6, n.3, p. 37-44, 2012. http://www.periodicoseletronicos.ufma.br/index. php/ccaatropica/article/view/882

SOARES, M.B.B.; GALLI, J.A.; TRANI, P.E.; MARTINS, A.L.M. Efeito da pré-embebição em solução bioestimulante sobre a germinação e vigor de sementes de Lactuca sativa L. Biotemas, v.25, p.17-23, 2012. https://doi.org/10.5007/2175-

$\underline{7925.2012 v 25 \mathrm{n} 2 \mathrm{p} 17}$

SOUZA, L.T.; ESPÍNDULA, M.C.; ROCHA, V.S.; DIAS, D.C.F.S.; SOUZA, M.A. Growth retardants in wheat and its effect in physiological quality of seeds. Ciência Rural, v.40, p.1431-1434, 2010. https://doi.org/10.1590/S0103-

$\underline{84782010000600031}$

TAIZ, L.; ZEIGER, E. Fisiologia vegetal. Artmed, Porto Alegre, Brasil. 719p., 2004.

YAMASHITA, O. M.; GUIMARÃES, S. C. Germinação das sementes de Conyza canadensis e Conyza bonariensis em função da disponibilidade hídrica no substrato. Planta Daninha, v.28, p.309-317, 2010. https://doi.org/10.1590/S0100-

83582010000200010

Recebido para publicação em 26/12/2016

Revisado em 16/10/2017

Aceito em 26/10/2017 